\title{
Effect of Particle Sizes of Raw Materials on the Luminescence Properties of $\mathrm{Eu}_{2} \mathrm{O}_{3}$-Doped $\mathrm{BaZrO}_{3}$ Phosphors
}

\author{
Jing Liu, Kun-Neng Chen, ${ }^{1}$ Wen-Cheng Tzou, ${ }^{1}$ \\ Mau-Phon Houng, ${ }^{2}$ Yi-Tang Chiu, ${ }^{3}$ and Cheng-Fu Yang ${ }^{3 *}$ \\ School of Information Engineering, Jimei University, Xiamen, Fujian 361021, PR China \\ ${ }^{1}$ Department of Electro-Optical Engineering, Southern Taiwan University, Tainan, Taiwan 710, R.O.C. \\ ${ }^{2}$ Institute of Microelectronics, National Cheng-Kung University, Tainan, Taiwan 701, R.O.C. \\ ${ }^{3}$ Department of Chemical and Material Engineering, National University of Kaohsiung, \\ Kaohsiung 811, Taiwan, R.O.C.
}

(Received September 30, 2016; accepted December 22, 2016)

Keywords: $\mathrm{Eu}_{2} \mathrm{O}_{3}$-doped $\mathrm{BaZrO}_{3}$ phosphors, raw materials, particle size, nanoscale

In this study, the raw materials of $\mathrm{BaCO}_{3}$ and $\mathrm{ZrO}_{2}$ powders with different average diameters were used to prepare $\mathrm{BaZrO}_{3}: \mathrm{Eu}_{0.025}$ phosphors by the solid-state reaction method. The raw materials with different average diameters were prepared by mixing them by the ball milling method and/or grinding them in a nanoscale grinding machine. As different grinding processes were used, the $\mathrm{BaCO}_{3}$ and $\mathrm{ZrO}_{2}$ powders had the average diameters of 2124, 707, 645, and $496 \mathrm{~nm}$. When raw materials with the average diameter of $2124 \mathrm{~nm}$ were used and the calcination temperature was changed from 1100 to $1400{ }^{\circ} \mathrm{C}$, the $\mathrm{BaZrO}_{3}: \mathrm{Eu}_{0.025}$ phosphors showed two strong orange emission bands with peaks at the wavelengths of 574 and $596 \mathrm{~nm}$ and two weak emission bands with peaks at 620 and $650 \mathrm{~nm}$. The maximum intensity of the emission spectrum of the $\mathrm{BaZrO}_{3}: \mathrm{Eu}_{0.025}$ phosphors increased with increasing calcination temperature. When the raw materials with the average particle sizes of 707, 645, and $496 \mathrm{~nm}$ were used and the calcination temperature was changed from 950 to $1150{ }^{\circ} \mathrm{C}$, the $\mathrm{BaZrO}_{3}: \mathrm{Eu}_{0.025}$ phosphors showed one broad blue emission band with central wavelengths located at 464-466 $\mathrm{nm}$. In this study, we prove that when the sizes of the source materials are different, the luminescence properties of the $\mathrm{BaZrO}_{3}: \mathrm{Eu}_{0.025}$ phosphors will have large variations after they are calcined at different temperatures.

\section{Introduction}

The $\mathrm{BaZrO}_{3}$ ceramic, which has the perovskite cubic structure, can be doped easily by divalent or trivalent rare earth ions. It also possesses many outstanding properties such as high refractive index, wide energy band gap, low optical loss, chemical and photochemical stability, excellent mechanical, electrical, thermal, and optical properties, and perfect single-phase structure. ${ }^{(1,2)}$ To achieve long red persistent phosphors with high performance, various ion-doped barium zirconates $\left(\mathrm{BaZrO}_{3}\right)$ have been paid much attention and investigated. ${ }^{(3-6)}$ Eu-doped oxide phosphors have been intensively studied owing to their emission being centered at different light wavelengths. For example, Murthy et al. found that $\mathrm{YGdBO}_{3}$ doped with Eu generates emissions at 366, 594, 613 , and $629 \mathrm{~nm} .{ }^{(7)}$ Zambare and Murthy used the solid-state reaction method to investigate the 
properties of Eu-doped $\mathrm{YPVO}_{4}, \mathrm{Y}_{2} \mathrm{O}_{3}$, and $\mathrm{YLaVO}_{4}$ phosphors. ${ }^{(8)}$ They used 254-nm-wavelength irradiation to excite the photoluminescence emission spectra of $\mathrm{YPVO}_{4}: \mathrm{Eu}^{3+}(0.5 \%)$, which displayed photoluminescence (PL) emissions at $365,540,561,594$, and $611 \mathrm{~nm}$, and $\mathrm{Y}_{2} \mathrm{O}_{3}: \mathrm{Eu}^{3+}(0.5 \%)$, which displayed PL emissions at 536, 583, 589, 594, 600, 615, and $632 \mathrm{~nm}$.

$\mathrm{Eu}^{3+}$-doped $\mathrm{BaZrO}_{3}$ phosphors also show the merits of brightness and flexible industrial processing ability, and they are suitable for lighting and display devices. However, little work has been performed on the perovskite-type $\mathrm{BaZrO}_{3}$ prepared by different fabrication processes. Previously, the solid-state reaction method was explored to synthesize $\mathrm{BaZrO}_{3}: \mathrm{Eu}^{3+}$ phosphors. ${ }^{(5,9,10)}$ The luminescence properties and the effects of dopant concentration on the PL characteristics of $\mathrm{BaZrO}_{3}: \mathrm{Eu}^{3+}$ phosphors were investigated on the basis of excitation and emission spectra. Kanie et al. synthesized Eu-doped $\mathrm{BaZrO}_{3}$ fine particles with high crystallinity by the hydrothermal reaction method and they obtained spherical, rhombic dodecahedral, and flower-shaped $\mathrm{BaZrO}_{3}$ fine particles. ${ }^{(11)}$ They also found the effects of the size and shape of the prepared $\mathrm{BaZrO}_{3}$-based powder grains on the fluorescence properties of the Eu-doped $\mathrm{BaZrO}_{3}$ phosphors. ${ }^{(1)}$ Two strong bands at 596 and $618 \mathrm{~nm}$ corresponding to the ${ }^{5} \mathrm{D}_{0}-{ }^{7} \mathrm{~F}_{1}(596 \mathrm{~nm})$ and ${ }^{5} \mathrm{D}_{0}-{ }^{7} \mathrm{~F}_{2}(618 \mathrm{~nm})$ transitions of $\mathrm{eu}^{3+}$ ions were actually observed, respectively. The two important emission peaks at 574 and $650 \mathrm{~nm}$ corresponding to the ${ }^{5} \mathrm{D}_{0}-{ }^{7} \mathrm{~F}_{0}(574 \mathrm{~nm})$ and ${ }^{5} \mathrm{D}_{0}-{ }^{7} \mathrm{~F}_{3}(650 \mathrm{~nm})$ transitions of $\mathrm{Eu}^{3+}$ ions, respectively, were not observed in their prepared Eu-doped $\mathrm{BaZrO}_{3}$ phosphors. This result suggests that the particle sizes have a large effect on the properties of Eu-doped $\mathrm{BaZrO}_{3}$ phosphors. Nevertheless, no research studies have focused on the effect of the particle size of raw materials on the luminescent properties of $\mathrm{BaZrO}_{3}$-based phosphors.

Previously, we found that different calcining processes would affect the luminescent properties of $\mathrm{BaZrO}_{3}: \mathrm{Eu}_{0.025}$ powders. ${ }^{(5)}$ Therefore, in this study, we used raw materials with different particle sizes to synthesize the $\mathrm{BaZrO}_{3}: \mathrm{Eu}_{0.025}$ phosphors by the traditional solid-state reaction method and investigated the effect of particle sizes on the luminescent properties. First, we used the ball milling method to mix and grind the raw materials and the solid-state reaction method to directly calcine the $\mathrm{BaZrO}_{3}: \mathrm{Eu}_{0.025}$ powders at the temperature of $1100-1400{ }^{\circ} \mathrm{C}$. Second, the raw materials were mixed and ground by a nano-powder grinding machine to semimicron scale. After that process, the $\mathrm{BaZrO}_{3}: \mathrm{Eu}_{0.025}$ powders were calcined at temperatures of $1000-1150{ }^{\circ} \mathrm{C}$. We found that different sizes of the raw materials used as precursors resulted in the $\mathrm{BaZrO}_{3}$ phosphors having different optical properties.

In this study, the physical and optical properties of $\mathrm{BaZrO}_{3}$ powders with different particle sizes as a function of calcining temperature are presented. The raw materials with the average diameter of $2124 \mathrm{~nm}$ were calcined at $1100-1400{ }^{\circ} \mathrm{C}$ to form $\mathrm{BaZrO}_{3}: \mathrm{Eu}_{0.025}$ phosphors. They showed two strong orange emission bands with peaks at the wavelengths of 574 and $596 \mathrm{~nm}$ and two weak emission bands with peaks at around 620 and $650 \mathrm{~nm}$ under the excitation of the optimum optical wavelength of $271 \mathrm{~nm}$. When the average diameters of the raw materials were 707, 645, and 496 $\mathrm{nm}$, the two strong orange emission bands at the wavelengths of 574 and $596 \mathrm{~nm}$ and the two weak emission bands at around 620 and $650 \mathrm{~nm}$ were not observed in the $\mathrm{BaZrO}_{3}: \mathrm{Eu}_{0.025}$ phosphors. We found that the particle sizes of the source materials have considerably large effects on the properties of the emission spectrum of $\mathrm{BaZrO}_{3}: \mathrm{Eu}_{0.025}$ phosphors and we will investigate the luminescent properties of $\mathrm{BaZrO}_{3}: \mathrm{Eu}_{0.025}$ phosphors with different average diameters of raw materials in detail. 


\section{Experimental Procedures}

$\mathrm{BaZrO}_{3}: \mathrm{Eu}_{0.025}$ powder was synthesized by the solid-state reaction method. $\mathrm{BaCO}_{3}, \mathrm{ZrO}_{2}$, and $\mathrm{Eu}_{2} \mathrm{O}_{3}$ powders were weighed according to the composition formula $\mathrm{BaCO}_{3}+\mathrm{ZrO}_{2}+0.0125 \mathrm{Eu}_{2} \mathrm{O}_{3}$ $\left(\mathrm{BaZrO}_{3}: \mathrm{Eu}_{0.025}\right)$. Depending on the stoichiometric ratio, the reactants were ground by two different processes. For the first process, the raw materials of $\mathrm{BaCO}_{3}$ and $\mathrm{ZrO}_{2}$ powders were mixed and ground using agate balls of 10-20 mm diameter, and after being mixed in acetone, dried, and ground, the mixing powders were calcined at $1100-1400{ }^{\circ} \mathrm{C}$ for $2 \mathrm{~h}$. For the second process, the raw materials of $\mathrm{BaCO}_{3}$ and $\mathrm{ZrO}_{2}$ powders were also mixed and ground using the agate balls. After being mixed in acetone, dried, and ground, the mixing powders were put in a nanoscale grinding machine and then ground using agate balls with different average diameters: 1.2-2.0, 0.8-1.2, and $0.6-0.8 \mathrm{~mm}$, respectively. After those processes, the mixing powders were calcined at $950-1150{ }^{\circ} \mathrm{C}$ for $2 \mathrm{~h}$.

For the raw materials ground by different processes, a laser particle size analyzer (Brookhaven Instruments Corporation: 90PLUS) was used to determine the average particle sizes of the ground raw materials. Morphology variations of the ground $\mathrm{BaZrO}_{3}: \mathrm{Eu}_{0.025}$-based raw materials were measured by field emission scanning electron microscopy (FESEM). The crystalline structures of the calcined $\mathrm{BaZrO}_{3}: \mathrm{Eu}_{0.025}$ powders were measured on the basis of X-ray diffraction (XRD) patterns with $\mathrm{Cu} \mathrm{K} \alpha$ radiation $(\lambda=1.5418 \AA)$. The PL properties of the $\mathrm{BaZrO}_{3}: \mathrm{Eu}_{0.025}$ phosphors were recorded at room temperature in the wavelength range of 300-800 nm on a Hitachi F-4500 fluorescence spectrophotometer. Liu and Wang excited the $\mathrm{BaZr}_{1-\mathrm{x}} \mathrm{Eu}_{\mathrm{x}} \mathrm{O}_{3}$ powders $\left(\mathrm{BaZrO}_{3}\right.$ doped with $\mathrm{Eu}^{3+}$ ) with $\lambda_{e m}=597$ and $258 \mathrm{~nm}$, and they found that $258 \mathrm{~nm}$ had a better excitation effect on the $\mathrm{BaZr}_{1-x} \mathrm{Eu}_{x} \mathrm{O}_{3}$ powders. ${ }^{(12)}$ This result suggests that we would need to identify the optimum optical wavelength for exciting the $\mathrm{BaZrO}_{3}: \mathrm{Eu}_{0.025}$ powders. In this study, the $3 \mathrm{D}$-scanning process was used to find the optimum optical wavelength, which was dependent on the average diameters and calcining temperature of the $\mathrm{BaZr}_{1-x} \mathrm{Eu}_{x} \mathrm{O}_{3}$ phosphors. We found that for the $\mathrm{BaZrO}_{3}: \mathrm{Eu}_{0.025}$ phosphors, the optimum value was around $269-288 \mathrm{~nm}$, and the $\mathrm{BaZrO}_{3}: \mathrm{Eu}_{0.025}$ powders excited by other wavelengths had weaker PL intensities.

\section{Results and Discussion}

FESEM was used to examine the morphology of the ground $\mathrm{BaZrO}_{3}: \mathrm{Eu}_{0.025}$ powders, and Fig. 1 shows the FESEM images of the $\mathrm{BaZrO}_{3}: \mathrm{Eu}_{0.025}$ powders as a function of the grinding process. The observation results indicated that as the grinding process was changed, the particle sizes of raw materials apparently changed as well. When the agate balls of $10-20 \mathrm{~mm}$ diameter were used, as Fig. 1(a) shows, the particle sizes of the raw materials were of micrometer order and the average diameter was $2124 \mathrm{~nm}$. After the grinding process, the powders with the average diameter of 2124 $\mathrm{nm}$ were further ground using agate balls of a smaller diameter in a nanoscale grinding machine. As the agate balls had the diameter of 1.2-2.0 mm, as Fig. 1(b) shows, the particle sizes of the raw materials actually decreased, and the average diameter was $707 \mathrm{~nm}$. When smaller agate balls were used, for example, the diameters of the agate balls were $0.8-1.2$ and $0.6-0.8 \mathrm{~mm}$, as Figs. 1(c) and 1(d) show, the particle sizes of the raw materials actually decreased and the average diameters were 645 and $496 \mathrm{~nm}$, respectively. These results prove that the nanoscale grinding machine can be used to grind the raw materials into smaller sizes and the diameter of the agate balls used is an important factor affecting the particle sizes of the raw materials. 

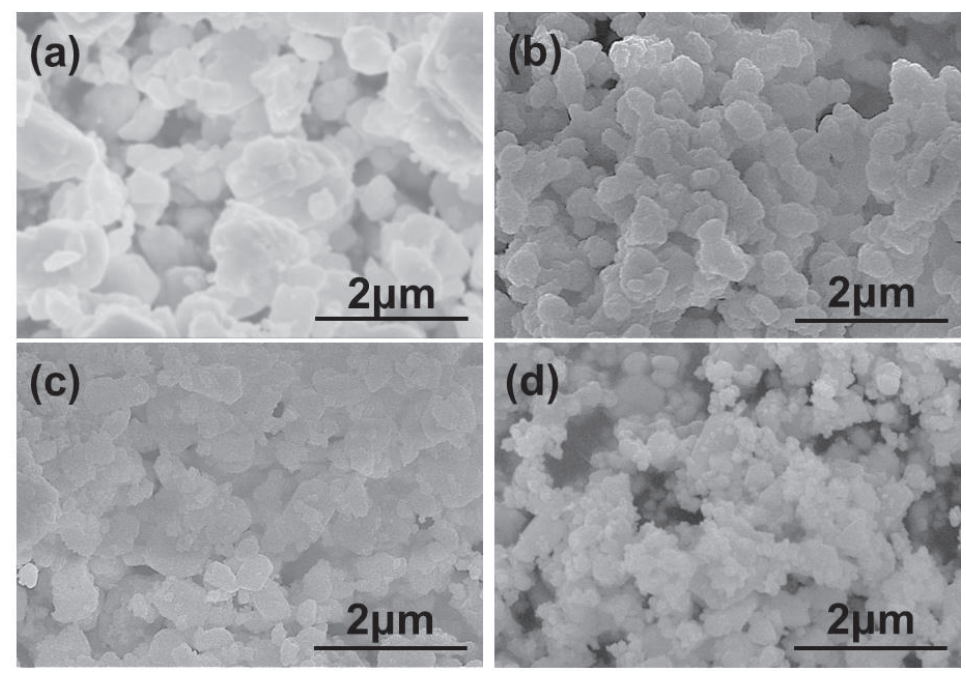

Fig. 1. Morphology of $\mathrm{BaZrO}_{3}: \mathrm{Eu}_{0.025}$ powders as a function of grinding process (diameter of agate balls). The diameters of agate balls used were (a) 10-20, (b) $1.2-2.0$, (c) $0.8-1.2$, and (d) $0.6-0.8 \mathrm{~mm}$.

In order to achieve good photoluminescence properties, the preparation of the $\mathrm{BaZrO}_{3}: \mathrm{Eu}_{0.025}$ powders forming the cubic perovskite phase is very important because the crystallization of the $\mathrm{BaZrO}_{3}: \mathrm{Eu}_{0.025}$ powders will affect their photoluminescence properties. Because the prepared raw materials of $\mathrm{BaZrO}_{3}: \mathrm{Eu}_{0.025}$ powders have different diameters, they affect the crystallization temperature, as confirmed by the XRD patterns in Fig. 2. The results in Fig. 2 will show that not all calcined $\mathrm{BaZrO}_{3}: \mathrm{Eu}_{0.025}$ powders have a stable cubic perovskite feature as the average diameter of the raw materials and the calcining temperature are changed. As Fig. 2(a) shows, when the average diameter of the raw materials of $\mathrm{BaZrO}_{3}: \mathrm{Eu}_{0.025}$ powders was $2124 \mathrm{~nm}$, the $2 \theta$ value of the (110) diffraction peak was constant at 30.18 as the calcining temperature increased from 1100 to $1400{ }^{\circ} \mathrm{C}$. As the calcining temperature was increased, the diffraction intensity of the (110) peak of the $\mathrm{BaZrO}_{3}: \mathrm{Eu}_{0.025}$ powders apparently increased. When the calcining temperature was $1100,1200,1300$, and $1400{ }^{\circ} \mathrm{C}$, the full widths at half maximum (FWHMs) for the (110) peak of the $\mathrm{BaZrO}_{3}: \mathrm{Eu}_{0.025}$ powders were $0.26,0.25,0.19$, and 0.17 , respectively. These results suggest that the crystallization [judged from the diffraction intensity and FWHM of the (110) peak] of $\mathrm{BaZrO}_{3}: \mathrm{Eu}_{0.025}$ powders calcined at higher temperatures is better than that of $\mathrm{BaZrO}_{3}: \mathrm{Eu}_{0.025}$ powders calcined at lower temperatures.

When the average diameter of the raw materials of $\mathrm{BaZrO}_{3}: \mathrm{Eu}_{0.025}$ powders was $707 \mathrm{~nm}$ and the calcining temperature was $1000^{\circ} \mathrm{C}$, as Fig. 2(b) shows, the calcined powders showed an amorphous phase. The $2 \theta$ value of the (110) diffraction peak remained at 30.16 as the calcining temperature increased from 1050 to $1150{ }^{\circ} \mathrm{C}$. The results in Fig. 2(b) show that as the calcining temperature was increased, the diffraction intensity of the (110) peak (FWHM) of the $\mathrm{BaZrO}_{3}: \mathrm{Eu}_{0.025}$ powders first increased (decreased) as the calcining temperature increased from 1000 to $1050{ }^{\circ} \mathrm{C}$, reached a maximum (minimum) at $1100{ }^{\circ} \mathrm{C}$, and then decreased (increased) at $1150^{\circ} \mathrm{C}$. The FWHMs for the (110) peak of the $\mathrm{BaZrO}_{3}: \mathrm{Eu}_{0.025}$ powders were $0.45,0.32$, and 0.35 , when the calcining temperatures were 1050,1100 , and $1150{ }^{\circ} \mathrm{C}$, respectively. The diffraction intensity of the (110) peak shows a similar trend to the FWHM of the (110) peak. These results suggest that when the raw materials 


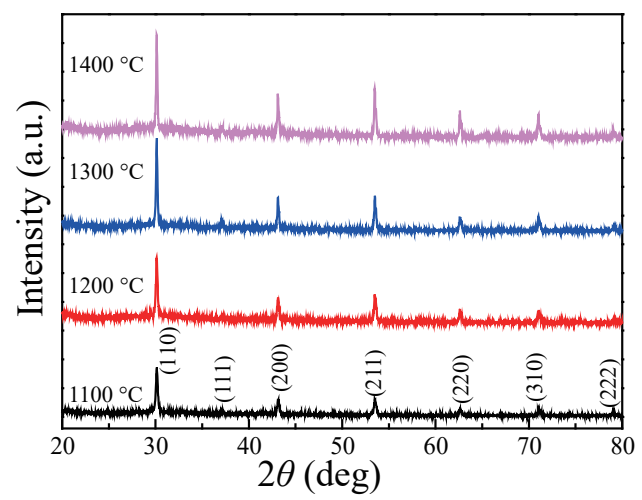

(a)

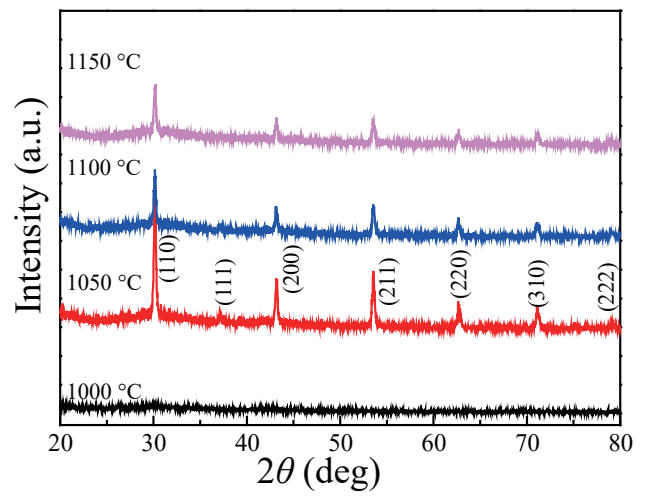

(c)

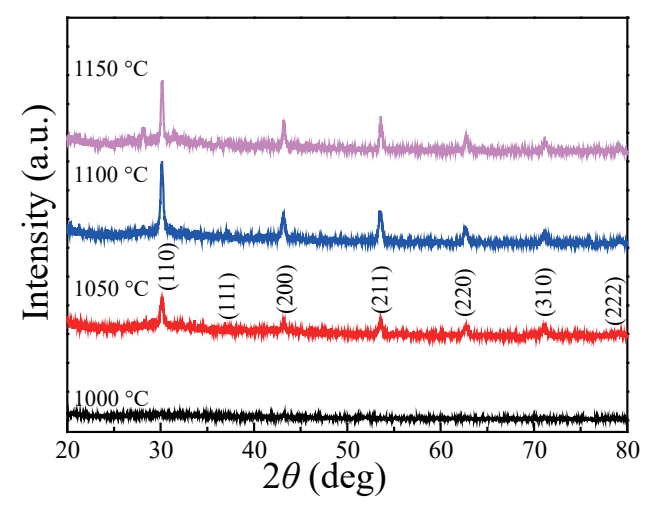

(b)

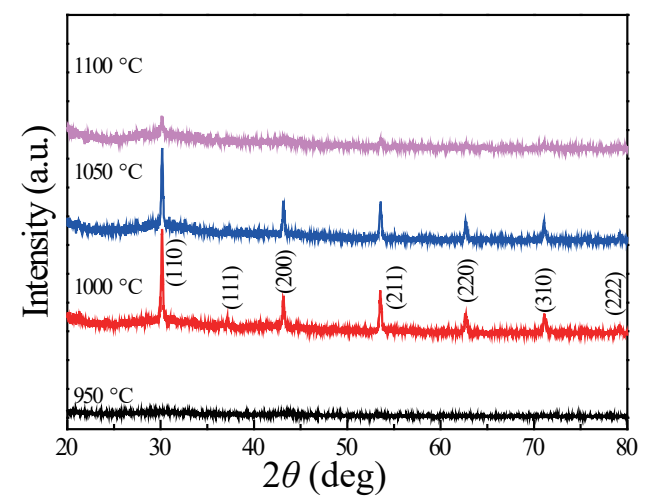

(d)

Fig. 2. (Color online) X-ray diffraction (XRD) patterns of $\mathrm{BaZrO}_{3}: \mathrm{Eu}_{0.025}$ powders as a function of average diameter of raw materials and calcining temperature. The average diameters of $\mathrm{BaZrO}_{3}: \mathrm{Eu}_{0.025}$ powders were (a) 2124 , (b) 707, (c) 645, and (d) $496 \mathrm{~nm}$.

of $\mathrm{BaZrO}_{3}: \mathrm{Eu}_{0.025}$ powders with the average diameter of $707 \mathrm{~nm}$ are used, the crystallization of the $\mathrm{BaZrO}_{3}: \mathrm{Eu}_{0.025}$ powders calcined at $1100{ }^{\circ} \mathrm{C}$ is better than that of the $\mathrm{BaZrO}_{3}: \mathrm{Eu}_{0.025}$ powders calcined at other temperatures.

When the average diameters of the raw materials of $\mathrm{BaZrO}_{3}: \mathrm{Eu}_{0.025}$ powders were 645 and $496 \mathrm{~nm}$, as Figs. 2(c) and 2(d) show, the calcined powders showed an amorphous phase when the calcining temperatures were 1000 and $950{ }^{\circ} \mathrm{C}$, respectively. If the calcining temperature was increased, the diffraction intensity (FWHM) of the (110) peak of the calcined $\mathrm{BaZrO}_{3}: \mathrm{Eu}_{0.025}$ powders first increased (decreased) as the calcining temperature increased from 1000 to $1050{ }^{\circ} \mathrm{C}$ for $645 \mathrm{~nm}$ and from 950 to $1000{ }^{\circ} \mathrm{C}$ for $496 \mathrm{~nm}$, reached a maximum (minimum) at $1050{ }^{\circ} \mathrm{C}$ for $645 \mathrm{~nm}$ and at $1000{ }^{\circ} \mathrm{C}$ for $496 \mathrm{~nm}$, and then decreased (increased) at $1100{ }^{\circ} \mathrm{C}$ for $645 \mathrm{~nm}$ and at $1050{ }^{\circ} \mathrm{C}$ for $496 \mathrm{~nm}$. Therefore, the average diameter of the raw materials of $\mathrm{BaZrO}_{3}: \mathrm{Eu}_{0.025}$ powders decreases, and the calcining temperature required to form the stable cubic perovskite feature is decreased. The results in Fig. 2 also suggest that for different average diameters of the raw materials of $\mathrm{BaZrO}_{3}: \mathrm{Eu}_{0.025}$ powders, the calcining temperature will have a large effect on the variations of the crystalline intensity and the $\mathrm{FWHM}$ for the (110) peak of $\mathrm{BaZrO}_{3}: \mathrm{Eu}_{0.025}$ powders.

The reason for the decrease in the required calcining temperature is that if the average diameter of the raw materials decreases, the surface areas of $\mathrm{BaCO}_{3}, \mathrm{ZrO}_{2}$, and $\mathrm{Eu}_{2} \mathrm{O}_{3}$ for the diffusion 
and reaction during the calcining process increase, thereby decreasing the required calcining temperature. However, as the average diameter of the raw materials decreases, the temperature for melting the raw materials decreases. That is the reason for the poor crystallization at higher calcining temperatures for raw materials with the average diameters of $707 \mathrm{~nm}\left(1150{ }^{\circ} \mathrm{C}\right), 645$ $\mathrm{nm}\left(1100{ }^{\circ} \mathrm{C}\right)$, and $496 \mathrm{~nm}\left(1100{ }^{\circ} \mathrm{C}\right)$. For the average diameter of $645 \mathrm{~nm}$, the $2 \theta$ value of the (110) diffraction peak was shifted from $30.16\left(1050{ }^{\circ} \mathrm{C}\right)$ to $30.18\left(1100\right.$ and $\left.1150{ }^{\circ} \mathrm{C}\right)$ with increasing calcining temperature. For the average diameter of $496 \mathrm{~nm}$, the $2 \theta$ value of the (110) diffraction peak was also shifted from $30.16\left(1000^{\circ} \mathrm{C}\right)$ to $30.18\left(1100^{\circ} \mathrm{C}\right)$ with increasing calcining temperature. The radii of $\mathrm{Zr}^{4+}, \mathrm{Ba}^{2+}$, and $\mathrm{Eu}^{3+}$ are $0.72,1.35$, and $0.947 \AA$, respectively. ${ }^{(5)}$ The shift of $2 \theta$ of the (110) diffraction peak to a higher value will cause a decrease in the lattice constant of the $\mathrm{BaZrO}_{3}$ perovskite cubic structure. Owing to the difference in the sizes of $\mathrm{Eu}^{3+}$ and $\mathrm{Zr}^{4+}$ ions, we believe that the reason to cause this result is that the more $\mathrm{Eu}^{3+}$ ions will occupy the $\mathrm{Zr}^{4+}$ sites. Those results in Fig. 2 show that $2 \theta$ value of (110) diffraction peak has been shifted to higher value. This result proves that as $\mathrm{Eu}^{3+}$ ions are substituted for the $\mathrm{Zr}^{4+}$ sites in the $\mathrm{BaZrO}_{3}: \mathrm{Eu}_{0.025}$ phosphors, the lattice constant increases and $2 \theta$ value of (110) diffraction peak will be shifted to smaller value.

The PL emission spectra of the $\mathrm{BaZrO}_{3}: \mathrm{Eu}_{0.025}$ powders with the average diameter of 2124 $\mathrm{nm}$ excited at a wavelength of $271 \mathrm{~nm}$ are shown in Figs. 3(a) and 4(a) for the light wavelength

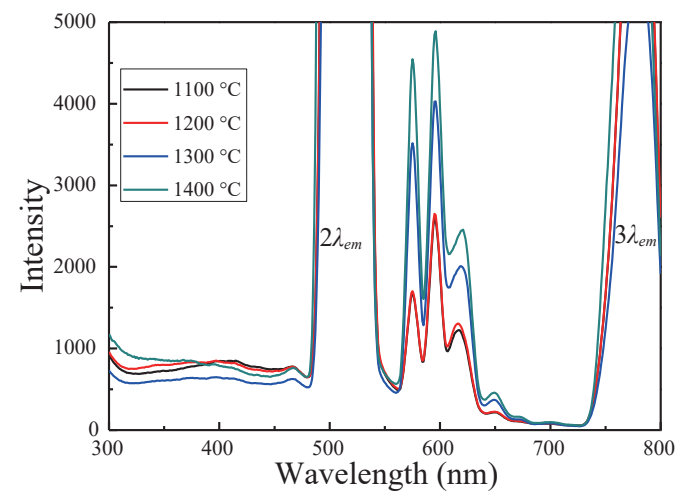

(a)

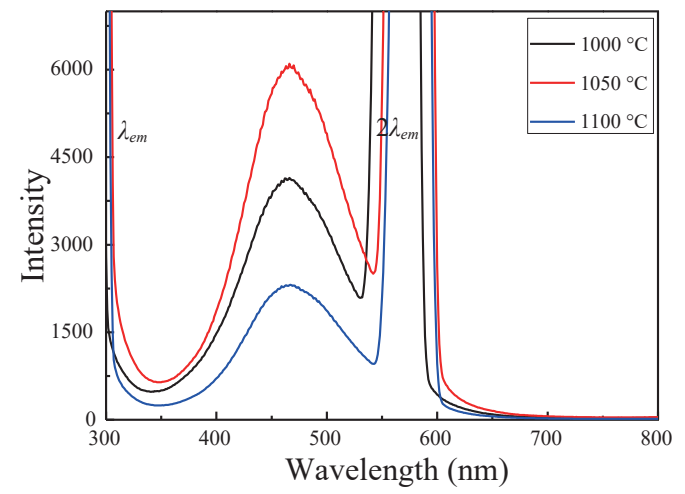

(c)

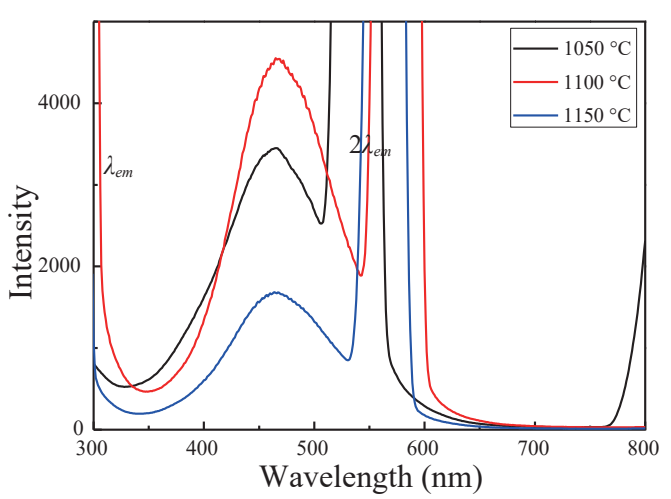

(b)

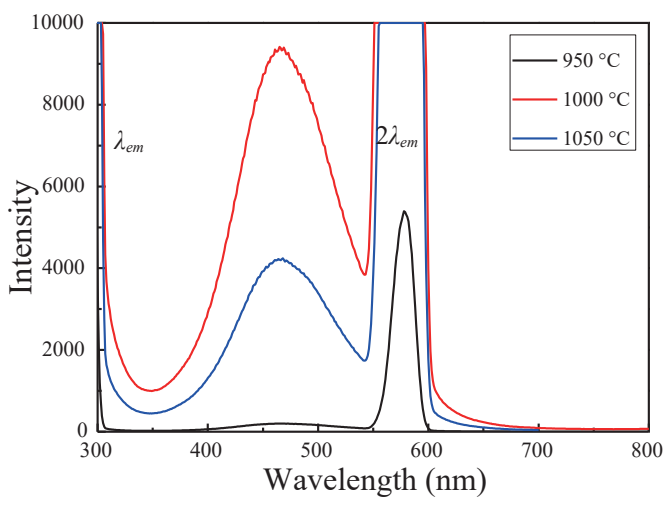

(d)

Fig. 3. (Color online) Emission spectrum of $\mathrm{BaZrO}_{3}: \mathrm{Eu}_{0.025}$ powders in the light wavelength range of 300-800 $\mathrm{nm}$ as a function of calcining temperature and particle sizes of raw materials. The average diameters of the raw materials were (a) 2124, (b) 707, (c) 645, and (d) $496 \mathrm{~nm}$ ( $\lambda_{e m}$ : main wavelength of excitation light). 


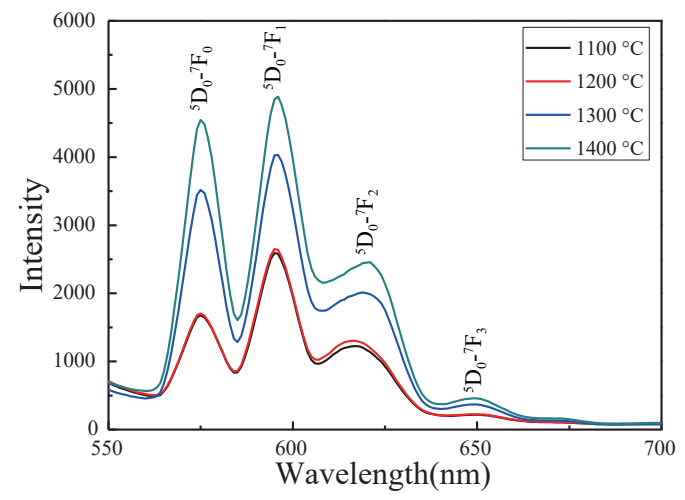

(a)

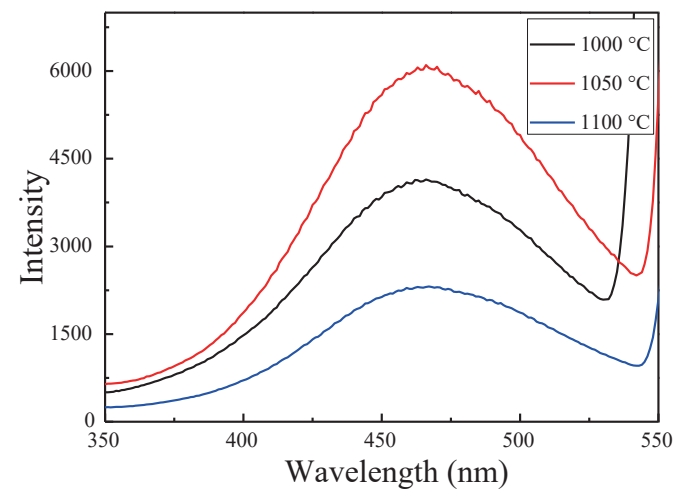

(c)

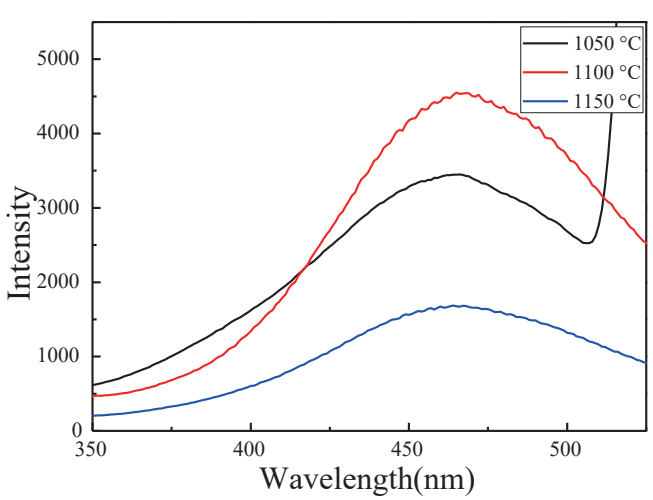

(b)

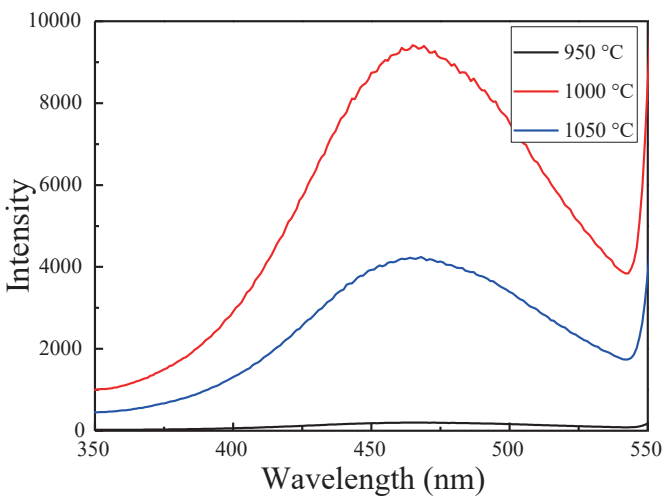

(d)

Fig. 4. (Color online) Emission spectrum of $\mathrm{BaZrO}_{3}: \mathrm{Eu}_{0.025}$ powders in different light wavelengths as a function of calcining temperature and particle sizes of raw materials. The average diameters of the raw materials for the emission spectrum were (a) $2124 \mathrm{~nm}$ for 550-700 nm, (b) $707 \mathrm{~nm}$ for 350-525 nm, (c) $645 \mathrm{~nm}$ for 350-550 nm, and (d) $496 \mathrm{~nm}$ for $350-550 \mathrm{~nm}$.

ranges of $300-800 \mathrm{~nm}$ and $550-700 \mathrm{~nm}$, respectively. For this type of $\mathrm{BaZrO}_{3}: \mathrm{Eu}_{0.025}$ phosphor, four emission peaks were revealed in the spectra. Previously, the spectra of $\mathrm{BaZr}_{1-x} \mathrm{Eu}_{x} \mathrm{O}_{3}\left(\mathrm{BaZrO}_{3}\right.$ doped with $\mathrm{Eu}^{3+}$ ) phosphors consisted of a series of resolved emission peaks at 574, 596, 616, 623, $651,673,696$, and $704 \mathrm{~nm}$, which can be assigned to ${ }^{5} \mathrm{D}_{0}-{ }^{7} \mathrm{~F}_{J}(J=0,1,2,3$, and 4$)$ transitions of $\mathrm{Eu}^{3+}$ ions, namely, the ${ }^{5} \mathrm{D}_{0}-{ }^{7} \mathrm{~F}_{0}(576 \mathrm{~nm}),{ }^{5} \mathrm{D}_{0}-{ }^{7} \mathrm{~F}_{1}(597 \mathrm{~nm}),{ }^{5} \mathrm{D}_{0}-{ }^{7} \mathrm{~F}_{2}(616$ and $623 \mathrm{~nm}),{ }^{5} \mathrm{D}_{0}-{ }^{7} \mathrm{~F}_{3}$ $(651 \mathrm{~nm})$, and ${ }^{5} \mathrm{D}_{0}-{ }^{7} \mathrm{~F}_{4}(673,696$, and $704 \mathrm{~nm})$ transitions. ${ }^{(12)}$ Liu and Wang's research results also showed that the emission intensities of the ${ }^{5} \mathrm{D}_{0}-{ }^{7} \mathrm{~F}_{0}(576 \mathrm{~nm}),{ }^{5} \mathrm{D}_{0}-{ }^{7} \mathrm{~F}_{1}(597 \mathrm{~nm})$, and ${ }^{5} \mathrm{D}_{0}-{ }^{7} \mathrm{~F}_{2}$ $(616,623 \mathrm{~nm})$ transitions almost had the same values even though the Eu concentrations in the $\mathrm{BaZr}_{1-x} \mathrm{Eu}_{x} \mathrm{O}_{3}$ phosphors were different. ${ }^{(12)}$ However, the $\mathrm{BaZrO}_{3}: \mathrm{Eu}_{0.025}$ phosphors investigated in this study had different results compared with those in Liu and Wang's research. As Figs. 3(a) and 4(a) show, the $\mathrm{BaZrO}_{3}: \mathrm{Eu}_{0.025}$ phosphors had two strong bands at 574 and $596 \mathrm{~nm}$ corresponding to the ${ }^{5} \mathrm{D}_{0}-{ }^{7} \mathrm{~F}_{0}(574 \mathrm{~nm})$ and ${ }^{5} \mathrm{D}_{0}-{ }^{7} \mathrm{~F}_{1}(596 \mathrm{~nm})$ transitions of $\mathrm{Eu}^{3+}$ ions, and two weak bands at 620 and $650 \mathrm{~nm}$ corresponding to the ${ }^{5} \mathrm{D}_{0}-{ }^{7} \mathrm{~F}_{2}(620 \mathrm{~nm})$ and ${ }^{5} \mathrm{D}_{0}-{ }^{7} \mathrm{~F}_{3}(650 \mathrm{~nm})$ transitions of $\mathrm{Eu}^{3+}$ ions, respectively. Splitting of the peaks of ${ }^{5} \mathrm{D}_{0}-{ }^{7} \mathrm{~F}_{2}(616,623 \mathrm{~nm})$ and ${ }^{5} \mathrm{D}_{0}{ }^{-}{ }^{7} \mathrm{~F}_{4}(673,696$, and $704 \mathrm{~nm})$ is not observed in Figs. 3(a) and 4(a). 
Yang et al. found that $\beta$-SiAlON:Eu phosphors exhibited a typical rodlike morphology. ${ }^{(13)}$ The low $\mathrm{Eu}^{2+}$ concentration would cause the $\beta$-SiAlON:Eu phosphors to have a blue emission and the high $\mathrm{Eu}^{2+}$ doping concentration would cause the $\beta$-SiAlON:Eu phosphors to have a green emission. ${ }^{(13)}$ This result suggests that when $\mathrm{Eu}_{2} \mathrm{O}_{3}$ is used as the dopant, the ${ }^{5} \mathrm{D}_{0}-{ }^{7} \mathrm{~F}_{J}(J=0,1,2,3$, and 4) transitions are not the only transitions of $\mathrm{Eu}^{3+}$ ions; some other transitions of $\mathrm{Eu}^{3+}$ ions exist, which will generate different color emissions. Thus, the results in Figs. 3(b)-3(d) and 4(b)-4(d) show that when the particles of raw materials of the $\mathrm{BaZrO}_{3}: \mathrm{Eu}_{0.025}$ powders are of the micrometer order $(707,645$, and $496 \mathrm{~nm})$, the $\mathrm{BaZrO}_{3}: \mathrm{Eu}_{0.025}$ phosphors largely differ from those with particles of the micrometer order (2124 nm). As Figs. 3(b)-3(d) and 4(b)-4(d) show, the emission peaks at $574,596,616,623,651,673,696$, and $704 \mathrm{~nm}$ assigned to ${ }^{5} \mathrm{D}_{0}-{ }^{7} \mathrm{~F}_{J}(J=0,1,2,3$, and 4) transitions of $\mathrm{Eu}^{3+}$ ions were not observed. Only one broad emission peak, which started at around $350 \mathrm{~nm}$ and ended at around $550 \mathrm{~nm}$, centered at $465-467 \mathrm{~nm}$, was obtained. Such emission spectra also show that the starting, central, and ending wavelengths were independent of the main peak of the excitation spectrum. The maximum emission intensities (PLmax values) of the $\mathrm{BaZrO}_{3}: \mathrm{Eu}_{0.025}$ phosphors in the transitions of the broad peaks are dependent on the average diameter of the raw materials and the calcining temperature.

Figures 4(b)-4(d) show that when the average diameters were 707, 645, and $496 \mathrm{~nm}$, the PLmax value of $\mathrm{BaZrO}_{3}: \mathrm{Eu}_{0.025}$ phosphors in the transition of the broad peak occurred in 1100-, 1050 -, and $1000-{ }^{\circ} \mathrm{C}$-calcined $\mathrm{BaZrO}_{3}: \mathrm{Eu}_{0.025}$ powders. Compared with the results shown in Figs. 2(a) and 4(a), the diffraction intensity (FWHM value) of the (110) peak increased (decreased) with increasing calcining temperature. The PLmax value of $\mathrm{BaZrO}_{3}: \mathrm{Eu}_{0.025}$ phosphors also increased with increasing calcining temperature. By comparing the results shown in Figs. 2(b)-2(d) and 4(b) -4(d), we found that for the calcined $\mathrm{BaZrO}_{3}: \mathrm{Eu}_{0.025}$ powders with the best crystallization [largest diffraction intensity and smallest FWHM of the (110) peak], the PLmax value of $\mathrm{BaZrO}_{3}: \mathrm{Eu}_{0.025}$ phosphors is the largest. These results prove that the crystallization of $\mathrm{BaZrO}_{3}: \mathrm{Eu}_{0.025}$ powders is the most important factor affecting their PL properties.

A comparison of the results shown in Figs. 4(b)-4(d) reveals two important trends in the emission spectra. The first is that the PLmax value of $\mathrm{BaZrO}_{3}: \mathrm{Eu}_{0.025}$ phosphors increased with decreasing average diameter of the raw materials. The PLmax values of $\mathrm{BaZrO}_{3}: \mathrm{Eu}_{0.025}$ phosphors were about 4550 (calcined at $1100{ }^{\circ} \mathrm{C}$ ), 6104 (calcined at $1050{ }^{\circ} \mathrm{C}$ ), and 9416 (calcined at 1000 ${ }^{\circ} \mathrm{C}$ ). Previously, we found that as the $\mathrm{Mn}^{+2}$ dopant concentration and the calcining temperature of $\mathrm{Zn}_{2} \mathrm{SiO}_{4}$ phosphors increase, the chance for $\mathrm{MnO}$ (or $\mathrm{MnO}_{2}$ ) to substitute for $\mathrm{ZnO}$ increases and hence the concentration of $\mathrm{Mn}^{+2}$ ions increases. Energy transfer between $\mathrm{Mn}^{+2}$ and $\mathrm{Mn}^{+2}$ ions is expected to occur, which will take the excitation energy very far from the absorption location. ${ }^{(14)}$ This result suggests that with a smaller average diameter of the raw materials of $\mathrm{BaZrO}_{3}: \mathrm{Eu}_{0.025}$ powders, the concentration of $\mathrm{Eu}^{3+}$ ions and their probability of substituting for $\mathrm{Zr}^{4+}$ increase. The opportunity for the energy transfer between $\mathrm{Eu}^{3+}$ and $\mathrm{Eu}^{3+}$ ions to occur is expected to increase; then, the PLmax value of $\mathrm{BaZrO}_{3}: \mathrm{Eu}_{0.025}$ phosphors increases. The second important trend is that with the average diameters of the raw materials of 707, 645, and $496 \mathrm{~nm}$, the PLmax value of the $\mathrm{BaZrO}_{3}: \mathrm{Eu}_{0.025}$ phosphors first increases, reaches a maximum, and then decreases as the calcining temperature is increased. Figure 2 shows that at the calcining temperatures of 1150, 1100, and $1050{ }^{\circ} \mathrm{C}$ for the powders with the average diameters of 707,645 , and $496 \mathrm{~nm}$, respectively, the degeneration of the crystallinity of $\mathrm{BaZrO}_{3}: \mathrm{Eu}_{0.025}$ powders is apparently observed, which is believed to be the cause of this trend. 


\section{Conclusions}

When the average diameter of the raw materials of $\mathrm{BaZrO}_{3}: \mathrm{Eu}_{0.025}$ powders was $2124 \mathrm{~nm}$ and the calcining temperature was increased from 1100 to $1400{ }^{\circ} \mathrm{C}$, the diffraction intensity (FWHM) of the (110) peak of the $\mathrm{BaZrO}_{3}: \mathrm{Eu}_{0.025}$ powders apparently increased (decreased). The $\mathrm{BaZrO}_{3}: \mathrm{Eu}_{0.025}$ phosphors had two strong bands corresponding to the ${ }^{5} \mathrm{D}_{0}-{ }^{7} \mathrm{~F}_{0}(574 \mathrm{~nm})$ and ${ }^{5} \mathrm{D}_{0}-{ }^{7} \mathrm{~F}_{1}(596 \mathrm{~nm})$ transitions of $\mathrm{Eu}^{3+}$ ions and two weak bands corresponding to the ${ }^{5} \mathrm{D}_{0}-{ }^{7} \mathrm{~F}_{2}(620 \mathrm{~nm})$ and ${ }^{5} \mathrm{D}_{0}-{ }^{7} \mathrm{~F}_{3}$ $(650 \mathrm{~nm})$ transitions of $\mathrm{Eu}^{3+}$ ions. The temperature needed for $\mathrm{BaZrO}_{3}: \mathrm{Eu}_{0.025}$ powders to form the perovskite cubic structure decreased as the average diameters of the raw materials decreased. When the average diameters of the raw materials of $\mathrm{BaZrO}_{3}: \mathrm{Eu}_{0.025}$ powders were 707, 645, and $496 \mathrm{~nm}$, the calcining temperatures that resulted in the maximum diffraction intensity (minimum FWHM) of the (110) peak of the $\mathrm{BaZrO}_{3}: \mathrm{Eu}_{0.025}$ powders were 1100,1050 , and $1000{ }^{\circ} \mathrm{C}$, respectively. $\mathrm{BaZrO}_{3}: \mathrm{Eu}_{0.025}$ phosphors made from raw materials with average diameters of 707, 645, and $496 \mathrm{~nm}$ all showed one broad blue emission band with central wavelengths located at 464-466 nm. Also, the calcined $\mathrm{BaZrO}_{3}: \mathrm{Eu}_{0.025}$ powders with the largest diffraction intensity and the smallest $\mathrm{FWHM}$ of the (110) peak had the largest PLmax value. These results prove that the crystallization of $\mathrm{BaZrO}_{3}: \mathrm{Eu}_{0.025}$ powders is the most important factor affecting their photoluminescence properties.

\section{Acknowledgements}

The authors would like to acknowledge the financial support under Grant Nos. MOST 104-2221-E-390-013-MY2 and MOST 105-2622-E-390-003-CC3. This work was also supported by NSFC projects under Grant No. 61505068, Fujian Provincial Natural Science Foundation under Grants No. 2015J01265, Science and Technology Plan Projects of Xiamen City under Grant No. 3502Z20143020, Program for Top Youth Talents in Universities of Fujian Province (TYTFJ 2015), and Program for New Century Excellent Talents in University of Fujian Province (NCETFJ 2016).

\section{References}

1 L. R. Macario, M. L. Moreira, J. Andrés, and E. Longo: CrystEngComm 12 (2010) 3612.

2 L. S. Cavalcante, J. C. Sczancoski, V. M. Longo, F. S. de Vicente, J. R. Sambrano, A. T. de Figueiredo, C. J. Dalmaschio, M. S. Li, J. A. Varela, and E. Longo: Opt. Commun. 281 (2008) 3715.

3 E. C. Subbarao, A. H. Heuer, and L. W. Hobbs: Science and Technology of Zirconia (Advances in Ceramics), (The American Ceramic Society Inc., Columbus, OH, 1981) p. 1.

4 R. Liang, D. A. Bonn, and W. N. Hardy: Physica C 304 (1998) 105.

5 K. N. Chen, C. M. Hsu, J. Liu, Y. T. Chiu, and C. F. Yang: Appl. Sci. 6 (2016) 22.

6 H. Iwahara, Y. Asakura, K. Katahira, and M. Tanaka: Solid State Ionics 168 (2004) 299.

7 K. V. R. Murthy, A. S. Sai Prasad, and M. Ramaligeshwar Rao: Physics Procedia 29 (2012) 70.

8 A. P. Zambare and K. V. R. Murthy: Arch. Phys. Res. 2 (2011) 46.

9 D. Sun, D. Li, Z. Zhu, J. Xiao, Z. Tao, and W. Liu: Opt. Mater. 34 (2012) 1890.

10 H. Zhang, X. Fu, S. Niu, and Q. Xin: J. Alloys Compd. 459 (2008) 103.

11 K. Kanie, Y. Seino, M. Matsubara, M. Nakaya, and A. Muramatsu: New J. Chem. 38 (2014) 3548.

12 X. Liu and X. Wang: Opt. Mater. 30 (2007) 626.

13 H. Yang, Q. Liu, Q. Wei, Z. Zhou, J. Wan, and G. Liu: J. Am. Ceram. Soc. 97 (2014) 3164.

14 W. C. Tzou, C. C. Diao, C. F. Yang, C. G. Kuo, and C. J. Huang: Ceram. Inter. 37 (2011) 1341. 